\title{
Mobile shopping cart abandonment: The roles of conflicts, ambivalence, and hesitation
}

\author{
Guei-Hua Huang ${ }^{1,2}$, Nikolaos Korfiatis ${ }^{1}$, Chun-Tuan Chang ${ }^{2 *}$ \\ Norwich Business School, University of East Anglia \\ Norwich, United Kingdom \\ E-mail:gueihua.huang@uea.ac.uk;n.korfiatis@uea.ac.uk \\ ${ }^{2}$ Department of Business Management, \\ National Sun Yat-Sen University, \\ Kaohsiung, Taiwan, \\ E-mail: ctchang@faculty.nsysu.edu.tw
}

Forthcoming:

Journal of Business Research

Note: aThis is an author accepted version scheduled to appear in the above journal. Please consult the final version at the publisher's website.

\footnotetext{
* Corresponding Author. National Sun Yat-Sen University, Kaohsiung, Taiwan
} 


\begin{abstract}
Though several industry reports have suggested that the rate of shopping cart abandonment is high in the mobile channel, the reasons for such abandonment remain relatively unexplored. Drawing on the cognition-affect-behavior (CAB) paradigm, this study aims to provide a conceptual framework explaining why consumers hesitate to use mobile channels for shopping and thus abandon their mobile shopping carts. Results from two studies show that mobile shopping cart abandonment is positively influenced by emotional ambivalence, a result of consumers ' conflicting thoughts. More specifically, emotional ambivalence amplifies consumers' hesitation at the checkout stage, leading to cart abandonment. However, if hesitant consumers are satisfied with the choice process during shopping, they are less likely to give up their mobile shopping carts. Based on the findings, this mobile channel study provides practical and theoretical implications for marketers and e-cart abandonment researchers, respectively.
\end{abstract}

Keywords: shopping cart abandonment; shopping hesitation; ambivalence; self-efficacy; choiceprocess satisfaction; conflicts 


\section{Introduction}

Mobile shopping, which refers to the purchase of goods or services from mobile devices such as smartphones and tablets via a wireless network (Wu \& Hisa, 2004), has become very popular among online shoppers. It currently accounts for one third of the US e-commerce market, and it is estimated to grow up to $300 \%$, faster than traditional e-commerce (Kumar, 2016). Its market importance and financial potential have prompted calls for knowledge and theories that can help us better understand the mobile consumer (e.g., Shankar, Venkatesh, Hofacker, \& Naik, 2010). One vital aspect of mobile shopping that interests both marketers and academics is mobile shopping cart abandonment behavior. We define mobile shopping cart abandonment as the behavioral outcome of leaving items in a mobile shopping cart without completing a purchase session. Industry reports have indicated that the shopping cart abandonment rate in the mobile channel is much higher than in the desktop based online channel (Kibo, 2016), resulting in high economic losses. The high abandonment rate also mirrors increased costs for multi-channel shoppers. Putting items in mobile shopping carts without checking out and then switching to desktop-based channels costs extra time and effort. This offsets the advantages of a mobile purchase.

Extant research has identified important factors for shopping cart abandonment in the online context (“e-cart abandonment"). Financial and psychological risks (Cho et al., 2006; Rajamma et al., 2009), and concerns about privacy intrusion and security breaches (Egeln \& Joseph, 2012; Kukar-Kinney \& Close, 2010) are some of the risks involved in online shopping cart abandonment. Perceived inconvenience has also been identified as a factor (Rajamma et al., 
2009). Some consumers use e-carts as a tool for organization and price comparison without actually intending to purchase (Close \& Kukar-Kinney, 2010; Kukar-Kinney \& Close, 2010). Although online shopping cart abandonment has been studied (see Table 1 for a summary of past studies), questions regarding why and how mobile shoppers abandon their mobile shopping carts remain relatively unexplored. The causes of mobile shopping cart abandonment may not be the same as those that apply in the online context because mobile purchasing has unique limitations and merits. For example, the small screen makes the device light and portable, but service providers may limit information search flexibility (Ghose, Goldfarb, \& Han, 2012). Although location identifiers provide recommendations based on consumers' locations, they arguably raise security and privacy concerns. The "double-edged sword" features of mobile devices entice prospective buyers to use the channel, but discourage them from completing transactions, resulting in high cart abandonment rates.

Thus, we aim to provide a theoretical framework upon which scholars can build, and offer practical implications to help managers understand mobile shopping cart abandonment. This study has the following objectives. First, drawing from the cognition-affect-behavior (CAB) paradigm, this study proposes a framework that incorporates the concepts of cognitive conflicts and emotional ambivalence to elaborate the mental flow underlying mobile shopping cart abandonment. Second, this study extends Cho et al. (2006) by distinguishing online shopping hesitation and cart abandonment, and examines whether hesitation at checkout serves as the mechanism underlying the ambivalence-abandonment relationship. Third, in consideration of Swant's (2016) contention that consumers seem to be dissatisfied with the process of product selection on the mobile channel, we propose that choice-process satisfaction acts as a moderator 
within the framework.

\section{$<$ Place Table 1 around here $>$}

\section{Theoretical background}

The cognition-affect-behavior paradigm describes the behavior formation process in which beliefs or thoughts determine affective responses as either favorable or unfavorable, thus forming behavioral intentions. The framework is effective in explaining consumer behavior, particularly in regard to individuals with high involvement. In this study, this paradigm is used as a basis to delineate mobile shopping cart abandonment since we aim to focus on mobile shopping abandonment behaviors of buyers, not browsers who have no intention of completing a purchase.

Priester and Petty (2001) postulated that objective assessment occurs prior to affect-oriented ambivalence and subcategorized it into intrapersonal and interpersonal conflicts. Intrapersonal conflicts refer to the extent of one's own positive and negative reactions to an object, while interpersonal conflicts describe the extent of disagreement between oneself and significant others. Based on this, we propose two intrapersonal conflicts: attribute conflicts regarding mobile shopping, and self-efficacy. Mobile shoppers may possess both positive and negative thoughts about mobile channels (attribute conflicts). Some consumers see themselves as 
incapable of handling the process, but have to go through it for a certain purpose such as transferring money via a mobile device (self-efficacy). Interpersonal conflicts are proposed as a third cognitive conflict because mobile shoppers may perceive conflicts between their own attitudes toward mobile shopping and those of reference groups.

Some researchers (e.g., Jonas, Broemer, \& Diehl, 2000; Priester \& Petty, 2001; Thompson, Zanna, \& Griffin, 1995) have argued that the concept of attitudes is complex and vague, and thus a univalent evaluation cannot explain its full complexity or reflect the true mental state of individuals. As such, they have proposed the concept of ambivalence which describes the occurrence of incompatible emotions or cognitions. The concept of ambivalence has been applied in important research topics such as recall and cognition (Ursavas \& HesapciSanaktekin, 2013), and green marketing (Chang, 2011). As this study adopts the CAB paradigm to explain the mental process of mobile shopping cart abandonment, we use the term "emotional ambivalence" to describe the mixed feelings toward mobile shopping induced by cognitive conflicts.

Figure 1 illustrates the proposed framework in which the three cognitive conflicts explain why emotional ambivalence emerges and, in turn, affects mobile shopping behavior. In addition, 
hesitation at checkout is included as a mediator between emotional ambivalence and mobile shopping cart abandonment. Finally, choice-process satisfaction is proposed to negatively moderate the relationship between hesitation at checkout and abandonment.

\section{$<$ Place Figure 1 around here $>$}

\section{Hypothesis development}

\subsection{Cognitive conflicts and emotional ambivalence}

There are many reasons why consumers engage in mobile shopping. Convenience and accessibility are the main determinants of mobile shopping satisfaction (Holmes et al., 2014), and mobility, efficiency and enjoyment also encourage consumers to make purchases via mobile devices (Kim et al., 2015). However, mobile shopping is also associated with some negative attributes that deter the completion of the transaction. Yang and Forney (2013) concluded that security and privacy concerns lead to anxiety, and Yang (2005) noted that access costs and risks related to credit cards are other factors that worry consumers in this context. This mix of simultaneously perceived positive and negative attributes generates conflicting thoughts, which are characterized by inconsistency and dissonance regarding mobile shopping. 
According to Baek (2010), attitudinal inconsistency is a form of psychological instability that leads to a fluctuation of emotions. When cognitive dissonance occurs, uncomfortable tension will follow (Lee \& Aaker, 2004). Russell et al. (2011) found that French consumers who possess both highly positive and highly negative views about the USA feel more ambivalent toward American brands. Likewise, when a person observes that mobile shopping is convenient and timely, pleasant feelings arise. If, at the same time, this same person also recognizes that mobile shopping involves privacy and security risks, such thoughts engender feelings of annoyance. Thus, a positive relationship between attribute conflicts and emotional ambivalence is hypothesized as follows.

H1: Consumers with a higher level of conflict among their perceptions of mobile shopping attributes will experience a higher level of emotional ambivalence.

Self-efficacy is defined as a judgment of the belief in one's ability to accomplish a certain task (Bandura, 1997). It is central to motivation because it determines what tasks are to be undertaken and what to invest in carrying out those tasks. It encourages the adoption of new technology (Compeau \& Higgins, 1995) and alleviates privacy concerns in online transactions (Akhter, 2014). We define self-efficacy as mobile users' perception regarding their ability to 
operate a mobile device. Self-efficacy also influences one's emotions. Fullagar et al. (2013) found that though performing in a music concert brings a sense of achievement, a lack of selfefficacy can elicit both positive and negative feelings regarding the performance. Likewise, a person may be attracted to the benefits of mobile shopping, but not dare to engage in it because of low self-efficacy, giving rise to ambivalent feelings. Thus, we have:

H2: Consumers with a lower level of self-efficacy regarding mobile shopping will experience a higher level of emotional ambivalence.

Social influence has long been proved as having a significant impact on human behavior. It is an important factor for intention and, subsequently, for behavior formation (Ajzen, 1991). We define interpersonal conflicts as the incongruence between a person's attitude toward mobile shopping and those of his/her important others.

People who encounter word-of-mouth that differs from their own opinions experience dissonance and feel uncomfortable (Kim \& Lennon 2011). Priester and Petty (2001) posited that when important others hold views that are strongly opposed to those of the focal individual, the latter is likely to have mixed feelings about the issue being considered. Further, Roster and Richins (2009) found that contradictions between a shopper's own opinion and those of 
important others lead to ambivalence in product replacement decisions. Consistent with this line of reasoning, emotional ambivalence occurs when mobile shoppers encounter the negative opinions of their important others, or vice versa. Thus, we have:

H3: Consumers with a higher level of interpersonal conflict regarding mobile shopping will experience a higher level of emotional ambivalence.

\subsection{Emotional ambivalence and mobile shopping cart abandonment}

Though ambivalent individuals feel both positive and negative emotions, negative emotions should be more influential because of negativity effects (Kanhouse \& Hanson, 1972).

Accordingly, negative feelings should have a dominant role in individuals' decision making. One strategy for avoiding negative feelings is to escape the object or event. Emotional ambivalence is also associated with discomfort and aversion (van Harreveld, van der Pligt, \& de Liver, 2009). Evidence has shown that discomfort negatively affects satisfaction (Chea \& Luo, 2008) and brand attitudes (Chang, 2011). Thus, we anticipate that ambivalent consumers will use mobile channels in the initial purchase stages (e.g., reading advertisements, collecting information or putting competing products in shopping carts for organizational purposes), but will be less likely to complete the purchase via that channel. 
H4: Emotional ambivalence increases the likelihood of mobile shopping cart abandonment.

\subsection{Hesitation at checkout}

Cho et al. (2006) defined online shopping hesitation as "postponing or deferring product purchases by having additional processing time before making final product-purchases on the Internet." They proposed three types of online hesitation: overall shopping hesitation, shopping cart abandonment, and hesitation to click the final payment button, suggesting that different factors contribute differently to the three types of hesitation. For example, perceived uncertainty factors are closely related to online shopping cart abandonment, but not to hesitation at checkout. Therefore, a distinction can be made between hesitation at checkout and cart abandonment. While mobile shopping cart abandonment is the behavioral outcome of leaving items in a mobile shopping cart without completing a purchase session, hesitation at checkout is conceptualized as having additional processing time at the checkout stage regardless of whether the transaction is completed or not.

Studies have shown that mobile shoppers often use mobile devices as a tool to research items and check prices (Nielsen, 2016). This implies that consumers' readiness to use mobile devices is limited to the early stages of shopping preparation. Shoppers are not keen to complete 
the process because ambivalent feelings about mobile shopping increase their aversion to the related risks. Therefore, it is very likely that when the selected products are placed in the shopping cart and payment is about to be made, these consumers will feel hesitant to proceed to the checkout stage. Thus, we have:

H5: Consumers who are more ambivalent will be more likely to hesitate at checkout during their mobile purchase.

Hesitant individuals tend not to make decisions in order to protect against, for example, damage to their self-esteem by being judged by others (Fee \& Tangney, 2000). Hesitance caused by anxiety explains why users refuse self-service technology (Meuter, Ostrom, Bitner, \& Roundtree, 2003). The effect of hesitation caused by too many choices leads consumers to leave the store empty-handed (Jessup, Veinott, Todd, \& Busemeyer, 2009). When consumers hesitate to make a purchase decision, they usually terminate the transaction (Ferrari, 1993). In the mobile context, even if products have been selected and are ready for checkout, hesitant consumers will be more likely to end their shopping process, leaving products in the cart. Thus, we have:

H6: Consumers who are more hesitant at checkout will be more likely to abandon their mobile 
shopping carts.

In brief, emotional ambivalence resulting in hesitation at checkout can discourage final decision making. In other words, emotional ambivalence positively influences shopping cart abandonment through hesitation at checkout. Formally, we posit that hesitation at checkout will mediate the relationship between emotional ambivalence and mobile shopping cart abandonment.

\subsection{Choice-process satisfaction}

Choice-process satisfaction, namely the degree of satisfaction with the choice process, pertains to the characteristics of a choice set, such as the availability of choices, assortment alignability, and decision quality (Fitzsimons, 2000; Zhang \& Fitzsimons, 1999). When consumers can effectively screen information and distinguish alternatives, choice-process satisfaction increases. However, when consumers have little knowledge of the product category or are faced with a large number of alternatives, they find it hard to identify a satisfying decision strategy (Heitmann, Lehmann, \& Herrmann, 2007). Thus, since product information, choice set size, and product presentation layouts are important channel factors, especially for mobile channels, choice-process satisfaction should play an important role in our framework. 
In particular, we argue that high levels of choice-process satisfaction weaken the positive link between hesitation at checkout and mobile shopping cart abandonment. Choice-process satisfaction depends on choice set size and assortment alignability (Heitmann et al., 2007). According to Diehl, van Herpen and Lamberton (2015), the change of assortment alters consumer expectation and varies the level of consumer satisfaction. A large assortment size leads to choice overload, which decreases decision confidence and satisfaction (Chernev, Böckenholt, \& Goodman, 2015), while a lack of choices relates to power deprivation (Inesi, Botti, Dubois, Rucker, \& Galinsky, 2011). Griffin and Broniarczyk (2010) found that satisfaction increases in the initial search stage buy decreases when options cannot be aligned. An aligned assortment helps consumers compare products and make judgments because it minimizes the cognitive effort required to make a given choice.

From a different perspective, Xia and Sudharshan (2002) contended that excessive interruptions caused by an overabundance of interactive features reduce choice-process satisfaction for online shoppers. Thus, we infer that the smooth cognitive process (e.g., fewer interruptions) will increase choice-process satisfaction and reduce negative feelings. From the above, we can conclude that choice-process satisfaction increases confidence in decision making, 
maintains consumers' powerful state and streamlines the cognitive process. These factors offset the negative feelings coexisting in ambivalent consumers, and shorten the time required for consumers to decide. Since this increases consumers' desire to possess the product(s), the purchase is more likely to be completed. Thus, we have:

H7: Choice-process satisfaction moderates the hesitation at checkout-abandonment relationship, such that the relationship is weaker at higher levels of choice-process satisfaction.

\section{Methods}

Two studies were conducted to test the proposed hypotheses. Study 1, using data from Taiwan, provides initial evidence that conflict-induced emotional ambivalence leads to mobile shopping cart abandonment (H1-H4). Study 2 used US data to replicate the findings of Study 1, and to further determine if $(i)$ the ambivalence-abandonment relationship is mediated by hesitation at checkout ( $\mathrm{H} 5$ and $\mathrm{H} 6$ ), and (ii) choice-process satisfaction weakens the hesitation at checkout-abandonment link (H7). Harman's single factor tests showed that the largest variance explained by a single factor is $26 \%$ and $32 \%$, respectively, in the two studies, indicating no issues with common method bias (CMB) (Podsakoff et al., 2003). The hypotheses were tested via covariance based structural equation modeling (SEM) using the R package Lavaan (Rosseel, 
2012) with a Maximum Likelihood estimator with robust standard errors for the estimation of significance levels.

\subsection{Study 1}

\subsubsection{Data collection and sample}

Data were collected from Taiwan where mobile shopping is burgeoning: $62.5 \%$ of mobile users in Taiwan have experience using mobile services, while 32.1\% have not purchased products via mobile services but have experience searching for product information via their mobile devices (Taiwan National Institute for Information Industry, 2012). The survey was posted for 30 days on the largest discussion forum called PTT. We received 232 responses (Mean age $=32.79, \mathrm{SD}=9.84,69.4 \%$ female), which were used for the analysis. The income level and age demographics of the sample were similar to those of the general population.

\subsubsection{Measures}

Scales were developed for measuring attribute conflicts and interpersonal conflicts for this study. The other constructs were adapted from prior studies and modified to fit the mobile shopping context (see Appendix A). 
Following Sweeney and Soutar (2001), we developed attribute conflicts measures by asking a focus group of $17 \mathrm{MBA}$ students to report and rank positive and negative attributes associated with mobile shopping. Their responses were collected, summed, and then ranked to obtain the top six positive attributes and top six negative attributes. The most positive attributes, in order of rank, were: convenient, timely, fast, entertaining, interesting, and fashionable. The negative attributes, from the most to least negative, were: unsafe, screen too small, unstable connection, complex operation, slow speed, and privacy concerns. We considered adopting the typical process for measuring conflicts via the discrepancy scores using the Griffin index (Thompson et al., 1995); however, the literature has cautioned that the results can be misleading. For example, Roster and Richins (2009) discovered that the discrepancy scores created by a Griffin score are unrelated to a measure of subjective ambivalence toward consumer replacement decisions when subjected to piecemeal regression procedures, as outlined by Edwards (2002).

The standard Griffin index is as follows:

$$
\text { Griffin }=\frac{(P+N)}{2}-|P-N|
$$

Where $P$ and $N$ represent the total score of positive and negative components.

Thus, we resorted to the extended Griffin index (Baek, 2010) in consideration of conflict 
intensity and similarity. The extended Griffin index suggests that a person with high intensity and low similarity values in regard to an object with multiple attributes is more likely to experience conflicts. Thus, attribute conflicts were defined as follows:

$$
\text { Attribute Conflicts }=\left(\frac{\sum_{i=1}^{n} w_{i} P_{i}}{2 n}+\frac{\sum_{i=1}^{n} w_{i} N_{i}}{2 n}\right)-\left(\frac{\sum_{i=1}^{n} w_{i} \sqrt{\left(P_{i}-N_{i}\right)^{2}}}{2 n}\right)
$$

Where:

- $w_{i}$ : the perceived importance of the attribute. For this study, we gave different weights to each of the six attributes for positive and for negative attributes according to their ranking obtained in the focus group. For example, "convenient" received weight =1, "timely" received weight $=0.83$, etc.;

- $\quad P, N$ : the total number of positive or negative attributes;

- $i$ : the individual attribute item;

- $n$ : the total number of items measured.

For measuring interpersonal conflicts, respondents were asked to rate their own attitudes toward mobile shopping and then to rate their perceptions of the attitudes of their important others. A 12-item semantic differential scale was used, anchored by positive-negative, favorableunfavorable, wise-unwise, beneficial-harmful, pleasant-unpleasant, and good-bad (Tormala \& DeSensi, 2008). Given that we used no weights, we applied the normalized absolute value of the attitude discrepancy between self-attitudes and important others' attitudes: 


$$
\text { Interpersonal Conflicts }=\left|\frac{S A i-I O_{i}}{S A i+I O_{i}}\right|
$$

Where: $S A$ and $I O$ denote self-attitudes and the attitudes of important others.

Self-efficacy was assessed using the measure from Davis and Tuttle (2013) and Venkatesh et al. (2003). Emotional ambivalence was drawn from Chang (2011) and Priester et al. (2007), from which only items related to mixed/torn feelings were selected. These were all measured using seven-point Likert scales, anchored by $1=$ strongly disagree and $7=$ strongly agree.

The measure of mobile shopping cart abandonment was adapted from Kukar-Kinney and Close (2010). Three-item, five-point scales were used (i.e., $1=$ never, $2=$ rarely, $3=$ sometimes, $4=$ very often, $5=$ always). To ensure that the Chinese version delivered the same meaning as the original English version, the questionnaire was back-translated into English and checked for consistency by a bilingual professor who was proficient in both English and Chinese.

\subsubsection{Measurement quality}

Several tests were conducted to assess whether the constructs had the appropriate degree of consistency, and the results are reported in Table 2. The values of item-to-total correlation for 
Item 4 for self-efficacy and Item 4 for abandonment were lower than the recommended thresholds of 0.5; thus, those items were excluded from the analysis (Hair, Black, Babin, \& Anderson, 2010). In the confirmation factor analysis (CFA), the Cronbach's alpha ( $\alpha$ ) for all constructs exceeded the threshold of 0.7. The smallest average variance extracted (AVE) was 0.59 , exceeding the 0.5 benchmark, suggesting that the convergent validity of the instruments was acceptable (Bagozzi \& Yi, 2012). In addition, the lowest square root of AVE among all constructs was 0.77 , higher than any correlations between any pair of constructs, indicating strong discriminant validity (Fornell \& Larcker, 1981) (see Table 3). All the model fit indexes are shown in Table 4.

\section{$<$ Place Tables 2, 3 and 4 around here $>$}

\subsubsection{Hypothesis testing}

As can be seen in Table 5, attribute conflicts were positively associated with emotional ambivalence $(\beta=0.38, p<0.001)$, supporting $\mathrm{H} 1$. The results also support $\mathrm{H} 2$, in that selfefficacy was negatively associated with emotional ambivalence $(\beta=-0.31, p<0.01)$. In line with $\mathrm{H} 3$, interpersonal conflicts were positively related to emotional ambivalence $(\beta=0.18, p<0.01)$. 
The effect of ambivalence on mobile shopping cart abandonment was found to be positive and significant $(\beta=0.15, p<0.05)$, supporting $\mathrm{H} 4$.

\section{$<$ Place Table 5 around here $>$}

\subsection{Study 2}

\subsubsection{Sample and measures}

We employed a sample of US consumers $(\mathrm{N}=226)$ sourced from a panel provided by a marketing research provider (Mean age $=34.44, \mathrm{SD}=10.16,49.6 \%$ female). In addition to measures used in Study 1, hesitation at checkout from Cho et al. (2006) and Wong and Yeh (2009), and choice-process satisfaction from Fitzsimons (2000) and Griffin and Broniarczyk (2010) were added in Study 2 to test hypotheses H5, H6 and H7.

\subsubsection{Measurement quality}

We followed the same procedures as in Study 1. We excluded Items 4 and 5 for selfefficacy, Item 7 for choice-process satisfaction and Item 4 for abandonment because their values of item-to-total correlation were lower than 0.5 . The Cronbach's alpha $(\alpha)$ for all constructs were 
above 0.7 , and all AVE scores were higher than the threshold of 0.5 , allowing us to conclude that the measures were valid.

\subsubsection{Hypothesis testing}

Attribute conflicts $(\beta=0.57, p<0.001)$, low self-efficacy $(\beta=-0.54, p<0.001)$, and interpersonal conflicts $(\beta=0.10, p<0.05)$ were found to significantly affect emotional ambivalence. The results supported H1, H2 and H3. The direct effect (c) of emotional ambivalence on mobile shopping cart abandonment (H4) was also found to be positive and significant $(\beta=0.31, p<0.001)$.

In the mediation model, the direct effect of emotional ambivalence on cart abandonment was reduced $(\beta=0.22, p<0.01)$, and the path coefficient for the impact of emotional ambivalence on hesitation at checkout (H5) was strongly significant $(\beta=0.27, p<0.001)$, as was that of hesitation at checkout on shopping cart abandonment $(\mathrm{H} 6)(\beta=0.56, p<0.001)$. Moreover, the bias-corrected confidence interval (CI) of the bootstrapping mediation test (Hayes, 2013) did not include zero $(95 \% \mathrm{CI}=0.06,0.17 ; 5000$ resamples); the results confirmed that hesitation at checkout partially mediates the effect of emotional ambivalence on shopping cart abandonment. 


\subsubsection{Moderating effects}

We tested $\mathrm{H} 7$ by assessing the hesitation at checkout $\times$ choice-process satisfaction interaction term as a means to predict cart abandonment. The interaction term was significant $(\beta=-0.12, p<0.01)$, indicating that the positive effect of hesitation at checkout on cart abandonment was buffered by higher levels of choice-process satisfaction, thus supporting H7. Following Aiken and West (1991), we plotted the moderating effect of choice-process satisfaction. Specifically, we estimated the effect of hesitation at checkout on cart abandonment under high (one standard deviation above the mean values) versus low (one standard deviation below the mean values) levels of choice-process satisfaction. Figure 2 shows that in the high choice-process satisfaction condition, choice-process satisfaction lowered cart abandonment when paired with high hesitation at checkout.

\section{$<$ Place Figure 2 around here $>$}

\section{Discussion}

Our results based on user experiences from two countries reveal the mental process underlying mobile shopping cart abandonment and support our proposed framework. Three 
major findings are noteworthy. First, intrapersonal conflicts (i.e., conflicts regarding mobile shopping attributes and low self-efficacy) and interpersonal conflicts are found to disturb consumers' emotions during mobile shopping, resulting in mobile shopping cart abandonment.

Second, this study reveals that emotionally ambivalent consumers tend to hesitate at the checkout stage after they have put products in the cart. These findings echo Chea and Luo's (2008)

findings, in that consumers are driven away when discomfort or mixed feelings arise. According to Close and Kukar-Kinney (2010), consumers use shopping carts as a research and organizational tool, with no intention to purchase immediately. This may also contribute to their ambivalence and hesitation at checkout. Third, hesitant consumers who are more satisfied with the choice process are less likely to abandon their mobile shopping carts as they have confidence that they have made the best choice.

\subsection{Theoretical implications}

This research offers several theoretical contributions. First, the authors extend the research context from general online shopping to mobile shopping by identifying factors that inhibit consumer buying behavior (i.e., mobile shopping cart abandonment). Second, using the $\mathrm{CAB}$ framework, this research echoes Pappas et al.'s (2016) finding that the causes of online shopping 
are complex and usually involve both cognitive and emotional components. The conflictsambivalence-hesitation-abandonment framework explains the mental process in which consumers cognitively, and, in turn, emotionally avoid completing a mobile shopping task. Third, this study extends Cho et al. (2006) and proposes that hesitation at checkout mediates the ambivalence-abandonment relationship, implying that shoppers do not always decide to forgo their shopping carts when they begin their shopping process, but experience a tension between completing and not completing the shopping task. Fourth, choice-process satisfaction is proposed as one of the boundary conditions for the framework. Our results indicate that when consumers feel hesitation at the point of checkout, they are less likely to abandon their shopping carts if they are satisfied with the choice process. Fifth, a parallel contribution of this study emerges from the cross-country data that increase the external validity of the conceptual framework. Several researchers in the area of international marketing (see Hoppner \& Griffith [2015] for a review) have suggested that the role of e-commerce in international marketing needs further investigation. Kukar-Kinney and Close (2010) also suggested that a cross-cultural study can provide further insight, since cross-cultural differences such as perceived risks could affect the abandonment behavior. 


\subsection{Managerial implications}

Our findings suggest several avenues by which retailers can reduce the likelihood of mobile shopping cart abandonment. First, consumers' cognitive conflicts must be minimized. One approach is to reduce the impact of negative attributes such as slow speed, privacy concerns, and small screens. Given the mobile phone's limited screen space, app/site designers should include only necessary elements on the shopping cart screen. Reducing clutter and using only essential elements will speed up the checkout process. Since flipping pages on small screens is annoying and ineffective when comparing products, we recommend presenting the most preferable products first, based on consumers' individual preferences, current location or shopping habits.

Second, several actions can facilitate a purchase during hesitation at checkout. The serendipity and unexpectedness of a contextual offer can increase consumers' positive affect, triggering the shopping motivation. For instance, mobile coupons for a nearby store can encourage instant purchases or increase order size. Limited special offers can pique consumers' interest and prompt buying behavior.

Third, choice-process satisfaction can be achieved via appropriate product categorizations or 
effective filter functions. This can help consumers locate target products quickly with less cognitive effort. Desktop-based promotional tools which may hinder the purchase process, such as pop-ups, live webcasts and promotional stickers, need to be carefully implemented on mobile channels as they can diminish choice-process satisfaction.

\section{Limitations and future research}

This study is not without limitations. First, since we investigated mobile shopping cart abandonment under the cognition-affect-behavior framework, other possible variables (e.g., various types of motivation) were omitted. This study also asked respondents to recall their recent mobile shopping experiences rather than considering a specific shopping episode.

Contextual factors such as product types, and consumption proximity may have been overlooked.

Second, other personality traits which may also influence ambivalence were not included, such as risk-taking propensity and the need for cognition. Third, this study used emotional ambivalence as the focal affect factor to represent consumers' emotional state. Other emotional states such as confusion, fear, and frustration may also occur during mobile shopping. Fourth, this study investigated mobile shopping behavior without examining factors in different stages of the shopping process. Future research could enrich this research stream by discussing these 
factors in depth in a longitudinal study or field experiment. 


\section{References}

Aiken, L. S., \& West, S. G. (1991). Multiple Regression: Testing and Interpreting Interactions. Newbury Park: Sage.

Ajzen, I. (1991). The theory of planned behavior. Organizational Behavior and Human Decision Processes, 50(2), 179-211.

Akhter, S. H. (2014). Privacy concern and online transactions: The impact of Internet self-efficacy and Internet involvement. Journal of Consumer Marketing, 31(2), 118-125.

Baek, Y. M. (2010). An integrative model of ambivalence. The Social Science Journal, 47(3), 609629.

Bagozzi, R. P., \& Yi, Y. (2012). Specification, evaluation, and interpretation of structural equation models. Journal of the Academy of Marketing Science, 40(1), 8-34.

Bandura, A. (1997). Self-efficacy: The Exercise of Control. New York: W.H. Freeman \& Company.

Chang, C. (2011). Feeling ambivalent about going green. Journal of Advertising, 40(4), 19-31.

Chea, S., \& Luo, M. M. (2008). Post-adoption behaviors of e-service customers: The interplay of cognition and emotion. International Journal of Electronic Commerce, 12(3), 29-56.

Chernev, A., Böckenholt, U., \& Goodman, J. (2015). Choice overload: A conceptual review and meta-analysis. Journal of Consumer Psychology, 25(2), 333-358.

Cho, C. H., Kang, J., \& Cheon, H. J. (2006). Online shopping hesitation. CyberPsychology \& Behavior, 9(3), 261-274.

Close, A. G., \& Kukar-Kinney, M. (2010). Beyond buying: Motivations behind consumers' online shopping cart use. Journal of Business Research, 63(9-10), 986-992.

Compeau, D. R., \& Higgins, C. A. (1995). Computer self-efficacy: Development of a measure and initial Test. Management Information System Quarterly, 19(2), 189-211.

Davis, J. M., \& Tuttle, B. M. (2013). A heuristic-systematic model of end-user information processing when encountering IS exceptions. Information \& Management, 50(2-3), 125133.

Diehl, K., van Herpen, E., \& Lamberton, C. (2015). Organizing products with complements versus 
substitutes: Effects on store preferences as a function of effort and assortment perceptions. Journal of Retailing, 91(1), 1-18.

Edwards, J. R. (2002). Alternatives to difference scores: Polynomial regression and response surface methodology. In F. Drasgow \& N. W. Schmitt (Eds.), Advances in Measurement and Data Analysis (pp. 350-400). San Francisco: Jossey-Bass.

Egeln, L. S., \& Joseph, J. A. (2012). Shopping cart abandonment in online shopping. Atlantic Marketing Journal, 1(1), 1-14.

Fee, R. L., \& Tangney, J. P. (2000). Procrastination: A means of avoiding shame or guilt? Journal of Social Behavior and Personality, 15(5), 167-184.

Ferrari, J. R. (1993). Christmas and procrastination: Explaining lack of diligence at a "real-world" task deadline. Personality and Individual Differences, 14(1), 25-33.

Fitzsimons, G. J. (2000). Consumer response to stockouts. Journal of Consumer Research, 27(2), 249-266.

Fornell, C., \& Larcker, D. F. (1981). Evaluating structural equation models with unobservable variables and measurement error. Journal of Marketing Research, 18(1), 39-50.

Fullagar, C. J., Knight, P. A., \& Sovern, H. S. (2013). Challenge/skill balance, flow, and performance anxiety. Applied Psychology, 62(2), 236-259.

Ghose, A., Goldfarb, A., \& Han, S. P. (2012). How is the mobile Internet different? Search costs and local activities. Information Systems Research, 24(3), 613-631.

Griffin, J. G., \& Broniarczyk, S. M. (2010). The slippery slope: The impact of feature alignability on search and satisfaction. Journal of Marketing Research, 47(2), 323-334.

Hair, J. F., Black, W. C., Babin, B. J., \& Anderson, R. E. (2010). Multivariate Data Analysis (7th ed.). Upper Saddle River, New York: Pearson.

Hayes, A. F. (2013). Introduction to Mediation, Moderation, and Conditional Process Analysis: A Regression-Based Approach. Guilford Press.

Heitmann, M., Lehmann, D. R., \& Herrmann, A. (2007). Choice goal attainment and decision and consumption satisfaction. Journal of Marketing Research, 44(2), 234-250.

Holmes, A., Byrne, A., \& Rowley, J. (2014). Mobile shopping behaviour: Insights into attitudes, shopping process involvement and location. International Journal of Retail and 
Distribution Management, 42(1), 25-39.

Hoppner, J. J., \& Griffith, D. A. (2015). Looking back to move forward: A review of the evolution of research in international marketing channels. Journal of Retailing, 91(4), 610-626.

Inesi, M. E., Botti, S., Dubois, D., Rucker, D. D., \& Galinsky, A. D. (2011). Power and choice: Their dynamic interplay in quenching the thirst for personal control. Psychological Science, 22(8), 1042-1048.

Jessup, R. K., Veinott, E. S., Todd, P. M., \& Busemeyer, J. R. (2009). Leaving the store emptyhanded: Testing explanations for the too-much-choice effect using decision field theory. Psychology and Marketing, 26(3), 299-320.

Jonas, K., Broemer, P., \& Diehl, M. (2000). Attitudinal ambivalence. European Review of Social Psychology, 11(1), 35-74.

Kanhouse, D. E., \& Hanson, R. L. (1972). Negativity in evaluations. In E. E. Jones, D. E. Kanhouse, H. H. Kelley, R. E. Nisbett, S. Valins, \& B. Weiner (Eds.), Attribution: Perceiving the Causes of Behavior. Morristoun, New York: General Learning Press.

Kibo. (2016). eCommerce Performance Index Vol 31. Retrieved October 31, 2016, from http://www.marketlive.com/in-the-news/press/performance-index-v31.html

Kim, M., Chung, N., Lee, C.-K., \& Preis, M. W. (2015). Motivations and use context in mobile tourism shopping: Applying contingency and task-technology fit theories. International Journal of Tourism Research, 17(1), 13-24.

Kim, M., \& Lennon, S. J. (2011). Consumer response to online apparel stockouts. Psychology and Marketing, 28(2), 115-144.

Kukar-Kinney, M., \& Close, A. G. (2010). The determinants of consumers' online shopping cart abandonment. Journal of the Academy of Marketing Science, 38(2), 240-250.

Kumar, H. (2016). Mobile commerce trends to buy into. Marketing Insights, 28(1), 20-21.

Lee, A. Y., \& Aaker, J. L. (2004). Bringing the frame into focus: The influence of regulatory fit on processing fluency and persuasion. Journal of Personality and Social Psychology, 86(2), $205-218$.

Meuter, M. L., Ostrom, A. L., Bitner, M. J., \& Roundtree, R. (2003). The influence of technology anxiety on consumer use and experiences with self-service technologies. Journal of 
Business Research, 56(11), 899-906.

Moore, S., \& Mathews, S. (2008). An exploration of online shopping cart abandonment syndromea matter of risk and reputation. Journal of Website Promotion, 2(1-2), 71-88.

Nielsen. (2016). Most popular mobile shopping activities according to consumers in the United States as of 4th quarter 2015. In Statista - The Statistics Portal. Retrieved February 9, 2017, from https:/www.statista.com/statistics/199279/most-popular-us-mobile-shoppingactivities/

Oliver, R. L., \& Shor, M. (2003). Digital redemption of coupons: Satisfying and dissatisfying effects of promotion codes. Journal of Product \& Brand Management, 12(2), 121.

Pappas, I. O., Kourouthanassis, P. E., Giannakos, M. N., \& Chrissikopoulos, V. (2016). Explaining online shopping behavior with fsQCA: The role of cognitive and affective perceptions. Journal of Business Research, 69(2), 794-803.

Podsakoff, P. M., MacKenzie, S. B., Lee, J.-Y., \& Podsakoff, N. P. (2003). Common method biases in behavioral research: A critical review of the literature and recommended remedies. Journal of Applied Psychology, 88(5), 879-903.

Priester, J. R., \& Petty, R. E. (2001). Extending the bases of subjective attitudinal ambivalence: Interpersonal and intrapersonal antecedents of evaluative tension. Journal of Personality \& Social Psychology, 80(1), 19-34.

Priester, J. R., Petty, R. E., \& Park, K. (2007). Whence univalent ambivalence? From the anticipation of conflicting reactions. Journal of Consumer Research, 34(1), 11-21.

Rajamma, R. K., Paswan, A. K., \& Hossain, M. M. (2009). Why do shoppers abandon shopping cart? Perceived waiting time, risk, and transaction inconvenience. Journal of Product \& Brand Management, 18(3), 188-197.

Rosseel, Y. (2012). Lavaan: An R package for structural equation modeling. Journal of Statistical Software, 48(2), 1-36.

Roster, C. A., \& Richins, M. L. (2009). Ambivalence and attitudes in consumer replacement decisions. Journal of Consumer Psychology, 19(1), 48-61.

Russell, C. A., Russell, D. W., \& Klein, J. (2011). Ambivalence toward a country and consumers' willingness to buy emblematic brands: The differential predictive validity of objective and 
subjective ambivalence measures on behavior. Marketing Letters, 22(4), 357-371.

Shankar, V., Venkatesh, A., Hofacker, C., \& Naik, P. (2010). Mobile marketing in the retailing environment: Current insights and future research avenues. Journal of Interactive Marketing, 24(2), 111-120.

Swant, M. (2016). Why people choose to shop or not to shop on their phones. Retrieved October 31, 2016, from http:/www.adweek.com/news/technology/heres-why-people-choose-shopor-not-shop-their-phones-169419

Sweeney, J. C., \& Soutar, G. N. (2001). Consumer perceived value: The development of a multiple item scale. Journal of Retailing, 77(2), 203-220.

Taiwan National Institute for Information Industry. (2012). Intelligent identification service value chain analysis report. In Forseeing Innovative New Digiservice. Taipei.

Thompson, M. M., Zanna, M. P., \& Griffin, D. W. (1995). Let's not be indifferent about attitudinal ambivalence. In R. E. Petty \& J. A. Krosnick (Eds.), Attitude strength: Antecedents and consequences (pp. 361-386). Mahwah, New York: Lawrence Erlbaum Associates, Inc.

Tormala, Z. L., \& DeSensi, V. L. (2008). The perceived informational basis of attitudes: Implications for subjective ambivalence. Personality and Social Psychology Bulletin, 32(2), 275-289.

Ursavas, B., \& Hesapci-Sanaktekin, O. (2013). What happens when you're lost between happiness and sadness?: Effects on consumers' cognitive responses. Journal of Business Research, $66(7), 933-940$.

van Harreveld, F., van der Pligt, J., \& de Liver, Y. N. (2009). The agony of ambivalence and ways to resolve it: Introducing the MAID Model. Personality and Social Psychological Review, $13(1), 45-61$.

Venkatesh, V., Morris, M. G., Davis, G. B., \& Davis, F. D. (2003). User acceptance of Information technology: Toward a unified view. Management Information System Quarterly, 27(3), $425-478$.

Wong, J.-Y., \& Yeh, C. (2009). Tourist hesitation in destination decision making. Annals of Tourism Research, 36(1), 6-23.

Wu, J.-H., \& Hisa, T.-L. (2004). Analysis of e-commerce innovation and impact: A hypercube 
model. Electronic Commerce Research and Applications, 3(4), 389-404.

Xia, L., \& Sudharshan, D. (2002). Effects of interruptions on consumer online decision processes. Journal of Consumer Psychology, 12(3), 265-280.

Xu, Y., \& Huang, J.-S. (2015). Factors influencing cart abandonment in the online shopping process. Social Behavior and Personality: An International Journal, 43(10), 1617-1627.

Yang, K. C. (2005). Exploring factors affecting the adoption of mobile commerce in Singapore. Telematics and Informatics, 22(3), 257-277.

Yang, K., \& Forney, J. C. (2013). The moderating role of consumer technology anxiety in mobile shopping adoption: Differential effects of facilitating conditions and social influences. Journal of Electronic Commerce Research, 14(4), 334-347.

Zhang, S., \& Fitzsimons, G. J. (1999). Choice-process satisfaction: the influence of attribute alignability and option limitation. Organizational Behavior and Human Decision Processes, 77(3), 192-214. 


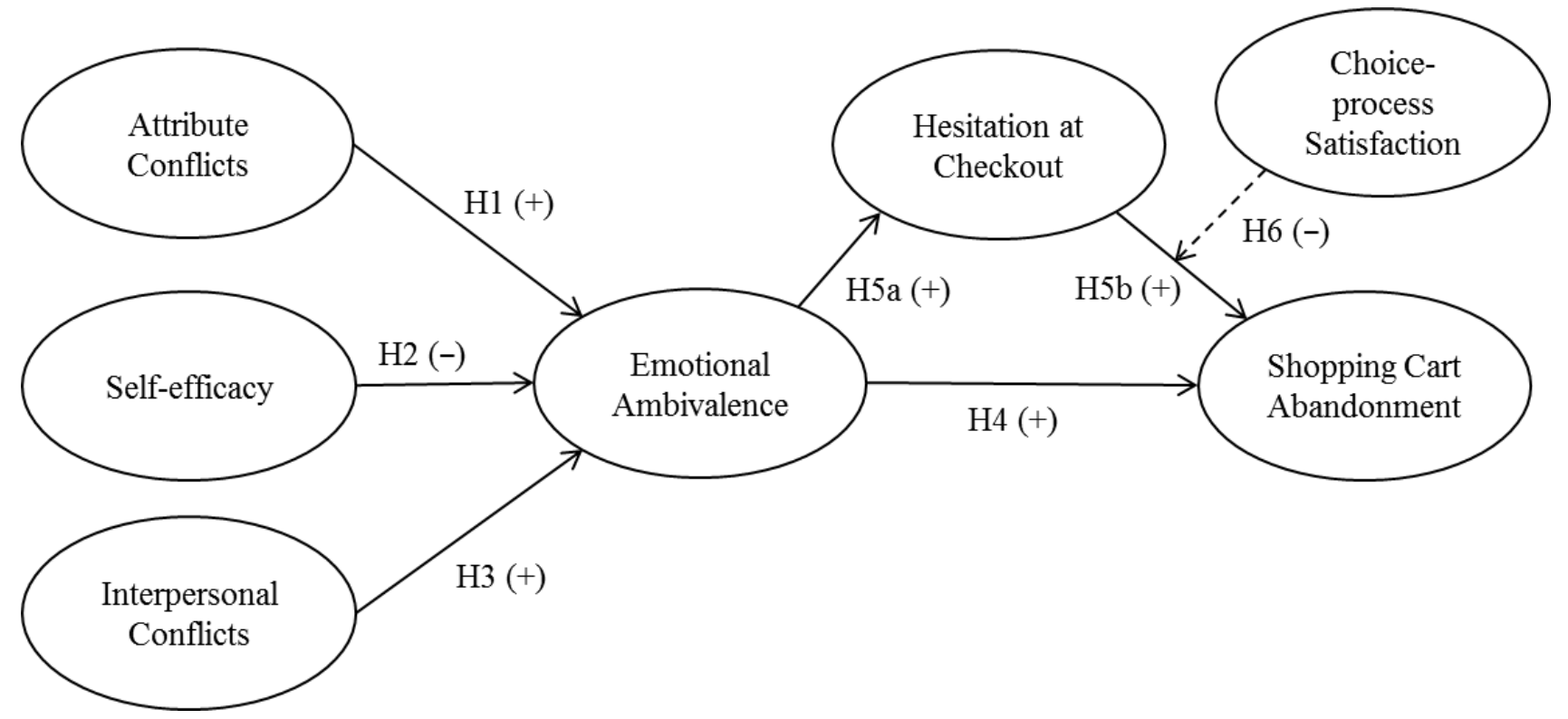

Figure 1. Conceptual framework 


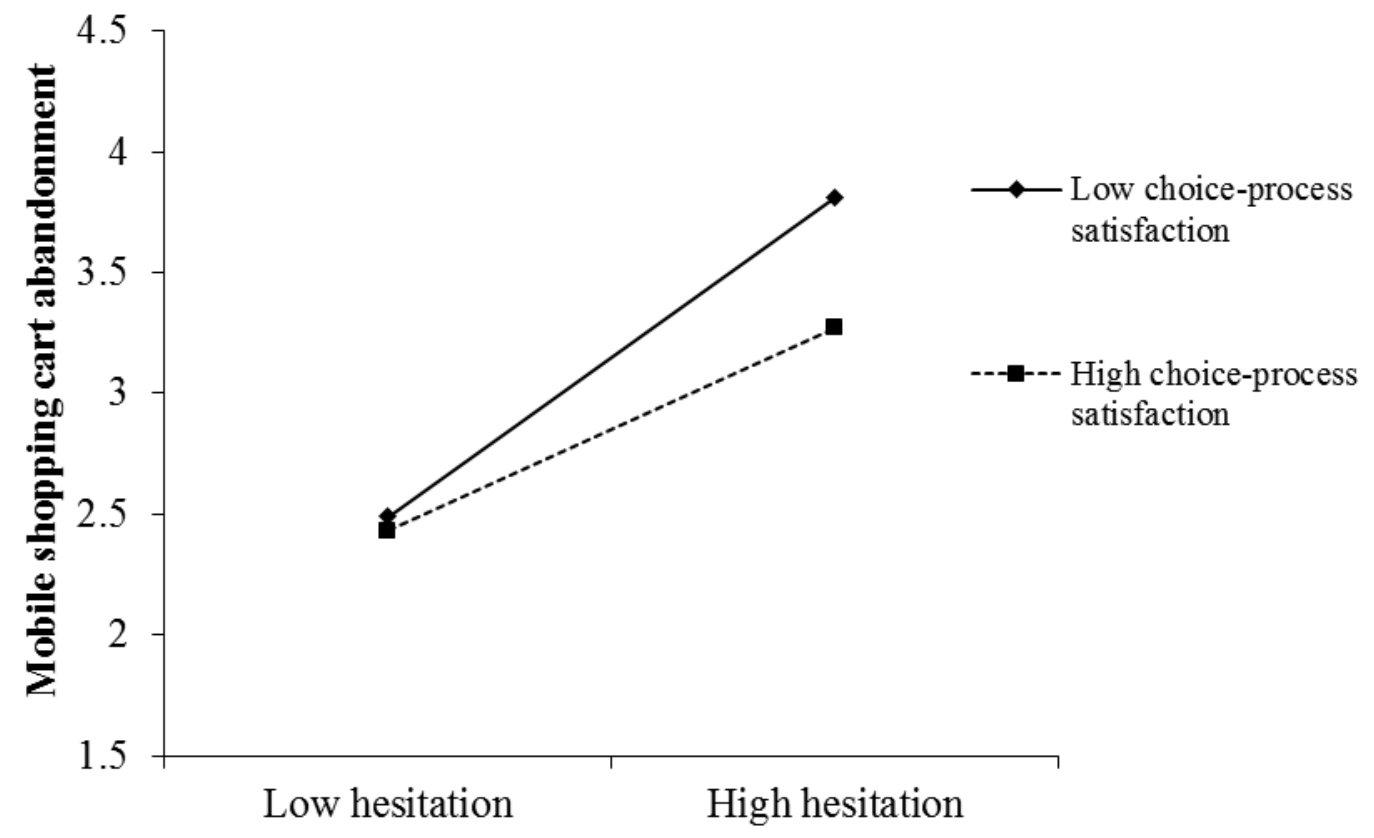

NOTE.-Low and high choice-process satisfaction plotted at one standard deviation below and above the mean.

Figure 2. The moderating effect of choice-process satisfaction 
Table 1 Summary of studies about online shopping cart abandonment

\begin{tabular}{|c|c|c|c|c|}
\hline Authors (year) & Data source & Method & Antecedents & Outcome variable \\
\hline Cho et al. (2006) & $\begin{array}{l}220 \text { US based } \\
\text { college students }\end{array}$ & Online survey & $\begin{array}{l}\text { (a) consumer characteristics, (b) contextual } \\
\text { factors, (c) perceived uncertainty factors, (d) } \\
\text { medium/channel innovation factors }\end{array}$ & $\begin{array}{l}\text { (a) online shopping } \\
\text { hesitation, (b) shopping cart } \\
\text { abandonment, (c) hesitation at } \\
\text { the final payment stage }\end{array}$ \\
\hline $\begin{array}{l}\text { Close and Kukar-Kinney } \\
\text { (2010) }\end{array}$ & -- & -- & $\begin{array}{l}\text { (a) concern over cost }(+),(b) \text { entertainment } \\
\text { use of e-cart }(+),(c) \text { organizational use of e- } \\
\text { cart }(+) \text {, }\end{array}$ & $\begin{array}{l}\text { Online shopping cart } \\
\text { abandonment }\end{array}$ \\
\hline Egeln and Joseph (2012) & $\begin{array}{l}133 \text { US based } \\
\text { university students }\end{array}$ & Survey & $\begin{array}{l}\text { (d) e-tailing perceived risk }(+) \text { : financial and } \\
\text { psychological risk }\end{array}$ & $\begin{array}{l}\text { Online shopping cart } \\
\text { abandonment }\end{array}$ \\
\hline $\begin{array}{l}\text { Kukar-Kinney and Close } \\
\text { (2010) }\end{array}$ & $\begin{array}{l}255 \text { respondents } \\
\text { from a US based } \\
\text { consumer panel }\end{array}$ & Online survey & $\begin{array}{l}\text { (a) entertainment value }(+),(\text { b) use of cart as } \\
\text { research and organizational tool }(+),(\text { c) } \\
\text { concern about costs }(+),(\text { d) privacy/security } \\
\text { concerns }(+),(\text { e) wait for sales }(+)\end{array}$ & $\begin{array}{l}\text { Online shopping cart } \\
\text { abandonment }\end{array}$ \\
\hline $\begin{array}{l}\text { Moore and Mathews } \\
\text { (2008) }\end{array}$ & Not provided & $\begin{array}{l}\text { Qualitative: } \\
\text { "third person" } \\
\text { approach, } \\
\text { questionnaire, } \\
\text { interview, }\end{array}$ & Perceived performance risk $(+)$ & $\begin{array}{l}\text { Online shopping cart } \\
\text { abandonment syndrome }\end{array}$ \\
\hline Oliver and Shor (2003) & 206 participants & online & perceived inequality & Hypothetical purchase \\
\hline
\end{tabular}


from online

consumer panel

experiment

707 US based undergraduate

students

Xu and Huang (2015)

\section{Rajamma et al. (2009)}

210 online shoppers

in China survey

online survey (a) perceived transaction inconvenience $(+)$,

(b) perceived risk $(+),(\mathrm{c})$ perceived waiting time $(+)$

(a) organization and research of products within the cart $(+),(b)$ comparisons with external websites $(+),(c)$ payment intention (non)completion question as

the proxy of online shopping cart abandonment

Online shopping cart abandonment

Online shopping cart abandonment 


\section{Table 2}

Reliabilities and factor loadings for constructs

\begin{tabular}{|c|c|c|c|c|c|c|c|c|}
\hline \multicolumn{5}{|c|}{ Study 1: Taiwan } & \multicolumn{4}{|c|}{ Study 2: USA } \\
\hline Construct & $\begin{array}{l}\text { Cronbach's } \\
\text { alpha }\end{array}$ & $\begin{array}{l}\text { Average } \\
\text { variance } \\
\text { extracted }\end{array}$ & Measures & $\begin{array}{l}\text { Standardized } \\
\text { factor loading } \\
\text { (t-value) }\end{array}$ & $\begin{array}{l}\text { Cronbach's } \\
\text { alpha }\end{array}$ & $\begin{array}{l}\text { Average } \\
\text { variance } \\
\text { extracted }\end{array}$ & Measures & $\begin{array}{l}\text { Standardized } \\
\text { factor loading } \\
\text { (t-value) }\end{array}$ \\
\hline \multirow[t]{4}{*}{ Self-efficacy } & 0.88 & 0.66 & EFF1 & $0.78(15.87)$ & 0.77 & 0.53 & EFF1 & $0.71(10)$ \\
\hline & & & EFF2 & $0.97(55.19)$ & & & EFF2 & $0.78(18.86)$ \\
\hline & & & EFF3 & $0.82(15.74)$ & & & EFF3 & $0.71(12.67)$ \\
\hline & & & EFF5 & $0.67(11.4)$ & & & & \\
\hline \multirow{5}{*}{$\begin{array}{l}\text { Emotional } \\
\text { ambivalence }\end{array}$} & 0.89 & 0.60 & AMB1 & $0.89(46.08)$ & 0.87 & 0.59 & AMB1 & $0.85(23.78)$ \\
\hline & & & AMB2 & $0.93(53.72)$ & & & AMB2 & $0.74(12.34)$ \\
\hline & & & AMB3 & $0.80(20.95)$ & & & AMB3 & $0.88(45.28)$ \\
\hline & & & AMB4 & $0.65(10.64)$ & & & AMB4 & $0.59(10.84)$ \\
\hline & & & AMB5 & $0.6(10.57)$ & & & AMB5 & $0.76(14.5)$ \\
\hline \multirow{3}{*}{$\begin{array}{l}\text { Mobile } \\
\text { shopping cart } \\
\text { abandonment }\end{array}$} & 0.81 & 0.59 & ABN1 & $0.82(19.7)$ & 0.88 & 0.72 & ABN1 & $0.89(40.25)$ \\
\hline & & & $\mathrm{ABN} 2$ & $0.8(16.16)$ & & & $\mathrm{ABN} 2$ & $0.85(27.34)$ \\
\hline & & & $\mathrm{ABN} 3$ & $0.69(10.51)$ & & & ABN3 & $0.8(20.04)$ \\
\hline \multirow{3}{*}{$\begin{array}{l}\text { Hesitation at } \\
\text { checkout }\end{array}$} & & & & & 0.92 & 0.71 & HES1 & $0.79(22.17)$ \\
\hline & & & & & & & HES2 & $0.84(25.48)$ \\
\hline & & & & & & & HES3 & $0.91(50.52)$ \\
\hline
\end{tabular}




\begin{tabular}{cclll} 
& & & HES4 & $0.81(23.26)$ \\
& & & HES5 & $0.88(30.73)$ \\
Choice- & & & & \\
process & & 0.56 & CPS1 & $0.62(9.27)$ \\
satisfaction & & & CPS2 & $0.78(20.41)$ \\
& & & CPS3 & $0.76(20.18)$ \\
& & & CPS4 & $0.79(12.25)$ \\
& & & CPS5 & $0.88(37.66)$ \\
& & & CPS6 & $0.83(21.24)$ \\
\hline
\end{tabular}


Table 3

Correlation matrix of the constructs from the CFA

\begin{tabular}{|c|c|c|c|c|c|c|c|c|c|}
\hline \multirow[b]{2}{*}{ Construct } & \multicolumn{8}{|c|}{ Study 1: Taiwan } & \\
\hline & $M$ & $S D$ & (1) & $(2)$ & (3) & (4) & (5) & & \\
\hline (1) Attribute conflicts & 0.98 & 0.41 & $N \boldsymbol{A}$ & & & & & & \\
\hline (2) Interpersonal conflicts & 0.09 & 0.10 & -0.11 & $N A$ & & & & & \\
\hline (3) Self-efficacy & 5.34 & 1.41 & 0.04 & 0.05 & 0.81 & & & & \\
\hline (4) Emotional ambivalence & 4.00 & 1.29 & 0.33 & 0.17 & -0.23 & 0.77 & & & \\
\hline \multirow[t]{2}{*}{ (5) Abandonment } & 2.49 & 1.09 & 0.07 & 0.19 & 0.15 & 0.22 & 0.77 & & \\
\hline & \multicolumn{8}{|c|}{ Study 2: USA } & \\
\hline Construct & $M$ & $S D$ & (1) & (2) & (3) & $(4)$ & (5) & (6) & (7) \\
\hline (1) Attribute conflicts & 0.24 & 0.56 & NA & & & & & & \\
\hline (2) Interpersonal conflicts & 0.06 & 0.09 & 0.17 & NA & & & & & \\
\hline (3) Self-efficacy & 6.26 & 0.92 & -0.55 & 0.01 & 0.73 & & & & \\
\hline (4) Emotional ambivalence & 2.42 & 1.40 & 0.67 & 0.13 & -0.57 & 0.77 & & & \\
\hline (5) Abandonment & 2.82 & 0.82 & 0.33 & 0.13 & -0.05 & 0.28 & 0.84 & & \\
\hline (6) Hesitation at checkout & 4.26 & 1.67 & 0.36 & 0.09 & -0.12 & 0.37 & 0.63 & 0.85 & \\
\hline $\begin{array}{l}\text { (7) Choice-process } \\
\text { satisfaction }\end{array}$ & 5.9 & 0.96 & -0.56 & -0.05 & 0.67 & -0.46 & -0.08 & -0.25 & 0.78 \\
\hline
\end{tabular}


Table 4

Fit indexes for all models

\begin{tabular}{|c|c|c|c|c|c|c|}
\hline & $\begin{array}{c}\text { Study } 1 \\
\text { CFA } \\
\text { Model }\end{array}$ & $\begin{array}{c}\text { Study } 1 \\
\text { Direct } \\
\text { Model }\end{array}$ & $\begin{array}{c}\text { Study } 2 \\
\text { CFA } \\
\text { Model }\end{array}$ & $\begin{array}{l}\text { Study } 2 \\
\text { Model } 1 \\
\text { (Direct) }\end{array}$ & $\begin{array}{c}\text { Study } 2 \\
\text { Model } 2 \\
\text { (Mediation) }\end{array}$ & $\begin{array}{c}\text { Study } 2 \\
\text { Model } 3 \\
\text { (Moderation) }\end{array}$ \\
\hline$\chi^{2}$ & 181.8 & 192.35 & 426.5 & 204.02 & 317 & 529.97 \\
\hline \multirow[t]{2}{*}{ (df) } & (69) & (104) & 233 & (90) & $(170)$ & (323) \\
\hline & $p<0.001$ & $p<0.001$ & $p<0.01$ & $p<0.001$ & $p<0.001$ & $p<0.001$ \\
\hline$\chi^{2} / \mathrm{df}$ & 2.62 & 1.85 & 1.83 & 2.27 & 1.86 & 2.06 \\
\hline GFI & 0.98 & 0.91 & 0.99 & 0.91 & 0.89 & 0.84 \\
\hline AGFI & 0.97 & 0.87 & 0.98 & 0.86 & 0.85 & 0.80 \\
\hline RMSEA & 0.08 & 0.06 & 0.06 & 0.08 & 0.06 & 0.07 \\
\hline CFI & 0.93 & 0.95 & 0.94 & 0.92 & 0.94 & 0.90 \\
\hline NFI & 0.90 & 0.9 & 0.88 & 0.87 & 0.88 & 0.83 \\
\hline Parsimonious & 0.68 & 0.68 & 0.75 & 0.65 & 0.71 & 0.70 \\
\hline NFI & & & & & & \\
\hline
\end{tabular}




\section{Table 5}

Summary of hypothesis tests

\begin{tabular}{|c|c|c|c|c|c|c|c|c|}
\hline \multirow[b]{3}{*}{ Directional paths } & \multirow{2}{*}{\multicolumn{2}{|c|}{$\begin{array}{c}\text { Study } 1 \text { (Taiwan) } \\
\text { Direct model }\end{array}$}} & \multicolumn{6}{|c|}{ Study 2 (USA) } \\
\hline & & & \multicolumn{2}{|c|}{ Direct model } & \multicolumn{2}{|c|}{ Mediation } & \multicolumn{2}{|c|}{ Moderation } \\
\hline & $\boldsymbol{\beta}$ & $t$-value & $\beta$ & $t$-value & $\beta$ & $t$-value & $B$ & $t$-value \\
\hline H1: Attribute Conflicts $\rightarrow$ Emotional Ambivalence & 0.38 & $5.79 * * *$ & 0.57 & $9.68^{* * * *}$ & 0.58 & $9.87 * * *$ & 0.57 & $5.44 * * *$ \\
\hline H2: Self-efficacy $\rightarrow$ Emotional Ambivalence & -0.31 & $-4.60 * *$ & -0.54 & $-4.27 * * *$ & -0.29 & $-3.45 * *$ & -0.28 & $-4.88 * *$ \\
\hline H3: Interpersonal Conflicts $\rightarrow$ Emotional Ambivalence & 0.18 & $2.92 * *$ & 0.10 & $2.13^{*}$ & 0.10 & $2.12 *$ & 0.10 & $2.09 *$ \\
\hline $\begin{array}{l}\text { H4: (c) Emotional Ambivalence } \rightarrow \text { Mobile Shopping } \\
\text { Cart Abandonment }\end{array}$ & 0.15 & $2.04 *$ & 0.31 & $3.88^{* * *}$ & 0.22 & $3.32 * *$ & 0.14 & 2.19 \\
\hline H5: Emotional Ambivalence $\rightarrow$ Hesitation at checkout & & & & & 0.27 & $3.73 * * *$ & 0.27 & $3.68 * *$ \\
\hline $\begin{array}{l}\text { H6: Hesitation at checkout } \rightarrow \text { Mobile Shopping Cart } \\
\text { Abandonment }\end{array}$ & & & & & 0.56 & $7.33 * * *$ & 0.54 & $5.99 * * *$ \\
\hline \multicolumn{9}{|l|}{ Mediating effect } \\
\hline Indirect $(\mathrm{a} * \mathrm{~b})$ & & & & & 0.15 & $3.47 * *$ & 0.14 & $2.58 * *$ \\
\hline Direct $(\mathrm{c})$ & & & & & 0.22 & $3.32 * *$ & 0.12 & 1.542 \\
\hline $\operatorname{Total}((a * b)+c)$ & & & & & 0.37 & $4.87 * * *$ & 0.25 & $2.57^{* *}$ \\
\hline \multicolumn{9}{|l|}{ Moderating effects } \\
\hline $\begin{array}{l}\text { H7: Choice-process satisfaction } \times \text { Hesitation at } \\
\text { checkout } \rightarrow \text { Abandonment }\end{array}$ & & & & & & & -0.12 & $-2.17 * *$ \\
\hline
\end{tabular}

Note: Age, gender and income were included in each study as control variables. ${ }^{*} \mathrm{p}<0.05,{ }^{* *} \mathrm{p}<0.01,{ }^{* * *} \mathrm{p}<0.001$. 


\section{Appendix A. Measurement items}

Attribute conflicts

Positive I think mobile shopping is ...

attributes:

ATT1 ATT6 convenient, timely, fast, entertaining, interesting, fashionable.

Negative I think mobile shopping is ...

attributes:

ATT7 ATT12 unsafe, uses too small a screen, uses an unstable connection, a complex operation, slow, involves privacy concerns.

\section{Interpersonal conflicts}

Self-attitudes: $\quad$ My attitude toward mobile shopping is...

INTP1 INTP6 positive-negative, favorable-unfavorable, wiseunwise, beneficial-harmful, pleasant-unpleasant, good-bad.

Other's My important others' attitudes toward mobile attitudes: shopping are...

INTP7 INTP12 positive-negative, favorable-unfavorable, wiseunwise, beneficial-harmful, pleasant-unpleasant, good-bad.

Self-efficacy EFF1 EFF5 I am (expect to become) proficient in using mobile devices for shopping.

I feel confident that I can (will be able to) use mobile devices for shopping. I could shop using mobile devices if I had enough time to complete the task.

I can shop using mobile devices if someone shows me how to do it first. (excluded from both studies) I could shop using mobile devices if I had only the built-in help facility for assistance. (excluded from Study 2)

\section{Emotional ambivalence}

AMB1 AMB5 I have strong mixed emotions both for and against

\section{Scale based on}

this study

this study

Davis and

Tuttle (2013);

Venkatesh et al.

(2003)

Chang (2011);

Priester et al. 
mobile shopping.

I feel conflict when thinking about mobile shopping.

I feel indecisive about mobile shopping.

I feel ambivalent about mobile shopping.

I can't make up my mind one way or another about

what is the best course of action for me to take

regarding mobile shopping.

\section{Hesitation at checkout}

Cho et al.

HES 1 HES5 I have hesitated to complete the checkout stage for (2006); Wong selected items while shopping using my mobile device.

It has taken some time for me to click the final payment button to purchase products via a mobile device.

I have thought twice at the checkout stage for a purchase via a mobile device.

I have spent some time deciding whether to press the payment button in a mobile shopping task.

I have waited awhile thinking about whether to finish the checkout process for items in the final payment stage.

\section{Mobile shopping cart abandonment}

Kukar-Kinney

ABN1 ABN4 How often do you place an item in the shopping cart, but do not buy it during the same session? and Close

How often do you close the webpage, or log off the mobile shopping application before you buy the item(s) in your shopping cart?

How often do you abandon your mobile shopping cart?

How often do you leave items in your mobile shopping cart without buying them?

\section{Choice-process satisfaction}

Fitzsimons

(2000); Griffin and

Broniarczyk 
satisfied)

(2010)

How happy were you with the process of choosing items you intended to buy? $(1=$ extremely unhappy, 7 = extremely happy)

I would be happy to choose from the same set of product options on my next purchase.

I found the process of deciding which products to put in the shopping cart interesting.

I thought the choice selection was good.

Several good options were available for me to choose between.

I found the process of deciding which product(s) to put in the mobile shopping cart frustrating (Reversed) (excluded from Study 2). 